\title{
Prevalence of smoking, alcohol consumption and metabolic syndrome in patients with psoriasis ${ }^{*}$
}

\author{
Esra Adişen ${ }^{1}$ \\ Funda Erduran ${ }^{1}$
}

\author{
Selda Uzun ${ }^{2}$ \\ Mehmet Ali Gürer ${ }^{1}$
}

DOI: http:/ / dx.doi.org/10.1590/abd1806-4841.20186168

\begin{abstract}
BACKGROUND: Coexistence of obesity, hypertension, insulin resistance and dyslipidemia is defined as metabolic syndrome (MBS), which is among the important risk indicators for cardiovascular diseases, diabetes and stroke. Smoking and alcohol consumption are the other factors which lead to an increase in the risk of cardiovascular disease.

Овјестіvе: To investigate the prevalence of metabolic syndrome, smoking and alcohol consumption in psoriasis patients and the relationship between disease severity and these factors.

METHODs: This cross-sectional study enrolled 563 patients with chronic plaque-type psoriasis, all of which completed a questionnaire and underwent a complete physical examination. Data about MBS components, psoriasis severity/duration, smoking and alcohol consumption, and cardiovascular diseases were recorded.

RESULTS: A total of 563 patients with ages ranging from 18 to 78 years were evaluated. Metabolic syndrome was found in $12.6 \%$ of the patients [central obesity $(38.7 \%)$, hypertension $(14.3 \%)$, dyslipidemia $(18.6 \%)$, diabetes $(9.2 \%)$ ], while $50.3 \%$ had smoking, and $3.3 \%$ had alcohol consumption. Patients with metabolic syndrome were older and more likely to have a longer disease duration than those without metabolic syndrome ( $p<0.05$ for each). The prevalence of metabolic syndrome was higher in women than in men. Psoriasis was more severe in patients with central obesity, diabetes and smoking than in those without $(\mathrm{p}<0.05$ for each).

STUDy LimitATIONS: Retrospective design.

CONCLUSIONS: Our results indicate that MBS is a risk factor for psoriasis patients with advanced age. The relationship between disease severity and obesity, diabetes, and smoking in psoriasis patients indicates that the patients should be informed about the potential metabolic risks and receive therapies for behavioral changes besides anti-psoriatic treatment in order to minimize these risks.
\end{abstract}

Keywords: Alcohol drinking; Metabolic diseases; Psoriasis; Smoking

\section{INTRODUCTION}

Psoriasis is a chronic inflammatory disease which is seen in $1-3 \%$ of the general population. It is suggested that $\mathrm{T}$ cell (Th)1 immune response in psoriasis has a role in the development of disorders like diabetes, hypertension, coronary heart disease, and obesity through systemic inflammatory response. ${ }^{1-5}$ In a study with 159.200 casos, Lindegard reported that obesity, diabetes, and myocardial infarction are more common in women with psoriasis. In their 1995 study. Henseler and Christophers ${ }^{7}$ reported that obesity, diabetes, hypertension and cardiovascular diseases are more common in psoriasis patients. ${ }^{6,7}$ Later studies have also yielded similar results. ${ }^{8-17}$ The most important data which increased our knowledge about psoriasis and comorbid diseases were obtained from clinical phase studies with immune biologics drugs, which included a large amount of psoriasis patients. These studies have also led to developments in the etiopathogenesis of psoriasis, and, since then, the relationship between the pathophysiology of psoriasis and some systemic diseases have begun to be established. All these developments indicate that psoriasis is not a disease limited to the skin, but also, that the systemic symptoms of chronic inflammation which lead to psoriasis, may be present in psoriasis patients. ${ }^{4,7}$

\footnotetext{
Received on 16.06.2016.

Approved by the Advisory Board and accepted for publication on 01.03.2017.

* Work performed at the Department of Dermatology, Gazi University Faculty of Medicine - Ankara, Turkey.

Financial support: None.

Conflict of interest: None.
}

Department of Dermatology, Gazi University Faculty of Medicine - Ankara, Turkey.

Dermatology Clinic, Kahramanmaraş Government Hospital - Kahramanmaraş, Turkey.

MAILING ADDRESS:

Esra ADIŞEN

E-mail: eozsoy@gazi.edu.tr 
The coexistence of clinical and metabolic disorders like obesity, hypertension, insulin resistance, and dyslipidemia is defined as metabolic syndrome (MBS) ${ }^{15}$ MBS is one of the important indicators of risk for cardiovascular diseases, diabetes and stroke. Smoking and alcohol use are other factors which lead to an increase in the risk cardiovascular disease. ${ }^{13,18-22}$ In this study, we investigated the prevalence of MBS, smoking and alcohol consumption in psoriasis patients, and the relationship between disease severity and these factors.

\section{METHODS}

This cross-sectional study was conducted at the Dermatology Department of Gazi University Medical School between January 2007 and October 2013. Patients who were 18 years or older and who had chronic plaque-type psoriasis were included in the study. All participants provided signed informed consent, and Gazi University Institutional Ethical Board reviewed the protocol and approved it. All psoriasis patients completed a questionnaire and underwent a complete physical examination. The information obtained from the anamnesis and physical examination findings was recorded and evaluated together with the medical records of the patients. All patients were assessed by two dermatologists (authors E.A and S.U), who recorded data about age, gender, height, weight, body mass index (BMI), waist circumference, psoriasis severity, duration of psoriasis, age at psoriasis onset, information about smoking and alcohol consumption habits, presence of diabetes, dyslipidemia, hypertension and other comorbid cardiovascular diseases of the patients. The evaluation was carried out together with the psoriasis outpatient clinic records and hospital medical records.

Psoriasis severity was evaluated using psoriasis area and severity index $=$ PASI scores, and scores above ten were accepted as severe.

Height, weight and waist circumference measurements were made with the routinely used instruments of the hospital. Body mass index was calculated by dividing weight $(\mathrm{kg})$ by the square of height $\left(\mathrm{m}^{2}\right)$. Waist circumference was measured at the midpoint between the lower margin of the least palpable rib and the top of the iliac crest, using a stretch-resistant measuring tape that was wrapped snugly around the patient. Measurement was made while the patient was standing upright and the tape was placed parallel to the floor.

The patients were asked about smoking/alcohol/psoriasis relationship (whether the habit started before, after or at the same time of the disease), the number of cigarettes smoked daily and duration of smoking/alcohol consumption of the patients who had smoking/alcohol consumption habit.

The presence of diabetes, dyslipidemia, hypertension and other comorbid cardiovascular diseases of the patients was assessed using the data collected from the medical history or reported by the patient. Patients with an established diagnosis of diabetes, dyslipidemia or hypertension requiring systemic treatment were included in the study.

Diagnostic criteria of International Diabetes Federation=IDF were used for the definition of MBS. ${ }^{18}$ Central obesity is the sine qua non parameter. Central obesity is defined as waist circumference $>94$ $\mathrm{cm}$ in males, $>80 \mathrm{~cm}$ in females or BMI $>30$. Any of two of the following criteria should also be present in addition to central obesity for diagnosis of MBS: hypertriglyceridemia [triglyceride level $\geq 150$ $\mathrm{mg} / \mathrm{dL}$ (1.7mmol/L) or receiving therapy for lipid disorder]; low HDL cholesterol [ $<40 \mathrm{mg} / \mathrm{dL}(1.03 \mathrm{mmol} / \mathrm{L})$ for males, $<50 \mathrm{mg} /$ $\mathrm{dL}(1.29 \mathrm{mmol} / \mathrm{L})$ for females or receiving therapy for lipid disorder]; elevated blood pressure [systolic blood pressure $\geq 130 \mathrm{mmHg}$ or diastolic blood pressure $\geq 85 \mathrm{mmHg}$ or receiving antihypertensive treatment] and elevated fasting plasma glucose $[\geq 100 \mathrm{mg} / \mathrm{dL}$ (5.6mmol/L) or diagnosis of type $2 \mathrm{DM}]$.

Statistical analysis was performed using SPSS 11.0 (Statistical Package for Social Sciences) program. Qualitative variables were summarized by percentages, and continuous quantitative variables were summarized by mean and standard deviation (SD). Kolmogrov-Smirnov normal distribution test (including PASI score) was performed for all variables ( $p>0.05$ in Kolmogrov-Smirnov test), and it was found to be normally distributed with all data. Therefore, in quantitative variables, mean and SD were used for descriptive statistics and Student-T test was used for inferential statistics. Student's t-test was used for comparison of age, age at onset, duration of disease and PASI scores of the study group according to MBS and its components. Chi-square test was used for comparison of MBS and components and distribution of smoking/alcohol use between genders. A p level of $<0.05$ was accepted as statistically significant.

\section{RESULTS}

General features of the study population are shown in table 1. A total of 563 patients (303 female, 260 male) with a mean age of $43.3 \pm 13.7$ years (range 18-78) who were registered at the psoriasis outpatient clinic were evaluated. Disease duration was between 1-51 (10.2 \pm 11.1$)$ years. PASI scores varied between 3.4-33 (6.4 \pm 6.8$)$. PASI score was 10 and above in 171 (30.4\%) cases. BMI values were $<18.5 \mathrm{~kg} / \mathrm{m}^{2}$ in $18(3.2 \%)$ patients, $18.5-25 \mathrm{~m}^{2}$ in $176(31.3 \%), 25$ $29.9 \mathrm{~kg} / \mathrm{m}^{2}$ in $215(38.2 \%),>30 \mathrm{~kg} / \mathrm{m}^{2}$ in $154(27.4 \%)$. Waist circumference varied between $65-120 \mathrm{~cm}(93.7 \pm 12.8)$. Diagnosis of central obesity ( $\mathrm{n}=218 ; 38.7 \%)$ was made with $\mathrm{BMI}>30$ in $154(27.4 \%)$ patients and waist circumference measurements in $64(11.3 \%)$ patient whose BMI <30. Of our patients, $81(14.3 \%)$ had hypertension, 105 (18.6\%) had dyslipidemia, $52(9.2 \%)$ had diabetes and 19 (3.3\%) had coronary artery disease.

MBS was detected in 71 (12.6\%) patients (Table 1). Of the patients, $50.3 \%(n=283)$ had been smoking 1-40 cigarettes daily for 0.5$52(22.2 \pm 18.9)$. There was the history of smoking in $59.6 \% \quad(n=155)$ of males and $42.2 \%(n=128)$ of females. Of the smokers, $54.7 \%$ of females and $38 \%$ of males smoked $1-10$ cigarettes daily; $40.6 \%$ of females and $54.8 \%$ of males smoked $11-40$ cigarettes daily; $4.6 \%$ of females and $7 \%$ of males smoked $>40$ cigarettes daily. Of the smokers, 69.6\% ( $n=197)$ stated that they had started smoking before the diagnosis of psoriasis, $30.3 \%(n=86)$ stated that they started smoking after or at the same time of the diagnosis of psoriasis. The ratio of alcohol use was 3.3\% ( $n=19)$; all of these cases were male, and they had been drinking alcohol before the diagnosis of psoriasis (Table 1). When the patients with or without MBS were compared with regard to age, gender and disease duration, MBS patients were older $(p<0.05)$, disease duration was longer $(p<0.05)$ and MBS was found more frequently among women $\left.\chi^{2}=21.2, p<0.05\right)$. On the other hand, a statistically significant difference was not detected between groups with regard to disease severity $(\mathrm{p}>0.05)$ (Table 2$)$. 


\begin{tabular}{|c|c|c|}
\hline Feature & \multicolumn{2}{|c|}{ Patients $(n=563)$} \\
\hline Sex & \multicolumn{2}{|c|}{$\mathrm{n}(\% *)$} \\
\hline \multirow[t]{2}{*}{ Female / Male } & \multicolumn{2}{|c|}{$303(53.9)$ / $260(46.1)$} \\
\hline & \multicolumn{2}{|c|}{ Mean \pm sd (min-max) } \\
\hline Age (years) & \multicolumn{2}{|c|}{$43.3 \pm 13.7(18-78)$} \\
\hline Age at onset of the disease & \multicolumn{2}{|c|}{$32.2 \pm 13.8(19-63)$} \\
\hline Duration of disease (years) & \multicolumn{2}{|c|}{$10.2 \pm 11.1(1-51)$} \\
\hline PASI score & \multicolumn{2}{|c|}{$6.4 \pm 6.8(3.4-33)$} \\
\hline Waist measurement (cm) & \multicolumn{2}{|c|}{$93.7 \pm 12.8(65-120)$} \\
\hline \multirow[t]{2}{*}{ Body Mass Index (BMI) value } & \multicolumn{2}{|c|}{$29.1 \pm 8.2(1-40)$} \\
\hline & \multicolumn{2}{|c|}{$\mathrm{n}(\% *)$} \\
\hline Central obesity & \multicolumn{2}{|c|}{$218(38.7)$} \\
\hline Hypertension & \multicolumn{2}{|c|}{$81(14.3)$} \\
\hline Hyperlipidemia & \multicolumn{2}{|c|}{$105(18.6)$} \\
\hline $\begin{array}{l}\text { Insulin resistance/type } 2 \text { diabetes } \\
\text { mellitus }\end{array}$ & \multicolumn{2}{|c|}{$52(9.2)$} \\
\hline Metabolic syndrome & \multicolumn{2}{|c|}{$71(12.6)$} \\
\hline \multicolumn{3}{|l|}{ Associating cardiovascular diseases } \\
\hline Coronary artery disease & \multicolumn{2}{|c|}{$19(3.3)$} \\
\hline History of smoking & \multicolumn{2}{|c|}{$283(50.3)$} \\
\hline $\begin{array}{l}\text { Number of patients started before } \\
\text { psoriasis }\end{array}$ & \multicolumn{2}{|c|}{$197(69.6)$} \\
\hline $\begin{array}{l}\text { Number of patients at the same } \\
\text { time/after psoriasis }\end{array}$ & \multicolumn{2}{|c|}{$86(30.3)$} \\
\hline Number of cigarettes & Female & Male \\
\hline $1-10$ & 70 & 59 \\
\hline $10-40$ & 52 & 85 \\
\hline$>40$ & 6 & 11 \\
\hline History of alcohol consumption & \multicolumn{2}{|c|}{$19(3.3)$} \\
\hline
\end{tabular}

*colon percentage

A statistically significant difference was not detected between psoriasis patients with or without hypertension and dyslipidemia with regard to age ( $p>0.05$ for each), disease duration $(p>0.05$ for each) and disease severity ( $p>0.05$ for each). When obese and non-obese psoriasis patients were compared, mean age was lower in non-obese patients $(p<0.05)$, the disease was more severe, and disease duration was longer in obese patients $(p<0.05)$. The disease was more severe in diabetic patients compared to non-diabetics $(p<0.05)$, however, there was not a significant difference between groups with regard to duration of disease and patient age ( $p>0.05$ for each).

In our study, ratio of coexistence of psoriasis, hypertension and dyslipidemia was greater among females. However, this distribution was not statistically significant $\left(\chi^{2}=14.6\right.$ and 13.4 , respectively, $\mathrm{p}>0.05)$, diabetes and central obesity were more frequent among females $\left(\chi^{2}=36.3, p<0.05\right)$ (Table 3$)$.

\begin{tabular}{|c|c|c|c|}
\hline Feature & $\begin{array}{c}\text { Metabolic } \\
\text { syndrome (+) } \\
(\mathrm{n}=71)\end{array}$ & $\begin{array}{c}\text { Metabolic } \\
\text { syndrome (-) } \\
(n=492)\end{array}$ & $\mathbf{P}$ \\
\hline \multicolumn{4}{|l|}{ Sex } \\
\hline Female, $\mathrm{n}(\%)$ & $43(60.5)$ & $260(52.8)$ & $<0.05^{*}$ \\
\hline Male, $\mathrm{n}(\%)$ & $28(39.4)$ & $232(47.1)$ & \\
\hline Age & $44.5 \pm 14.3$ & $42.1 \pm 13.1$ & $<0.05^{* *}$ \\
\hline Age at onset & $33.4 \pm 13.4$ & $31 \pm 14.2$ & $<0.05^{* *}$ \\
\hline $\begin{array}{l}\text { Duration of } \\
\text { disease (years) }\end{array}$ & $12.9 \pm 11.2$ & $7.4 \pm 7$ & $>0.05^{* *}$ \\
\hline PASI score & $4.7 \pm 4$ & $3.3 \pm 3.4$ & $<0.05^{* *}$ \\
\hline
\end{tabular}

* Chi-square test, $\chi^{2}=21.2$

** Student's t -test

TABLE 3: The relationship of age, psoriasis severity and duration with central obesity, hypertension, dyslipidemia and diabetes in psoriasis patients

\begin{tabular}{|c|c|c|c|}
\hline $\begin{array}{l}\text { Central } \\
\text { obesity }\end{array}$ & $\begin{array}{l}\text { Present } \\
(n=218)\end{array}$ & $\begin{array}{l}\text { Absent } \\
(\mathrm{n}=345)\end{array}$ & $\mathbf{P}$ \\
\hline Female/male & $129 / 89$ & $174 / 171$ & $<0.05^{*}$ \\
\hline Age† & $51.8 \pm 14.7$ & $42.2 \pm 7.6$ & $<0.05^{* *}$ \\
\hline PASI score & $4.9 \pm 4.2$ & $3.3 \pm 3.1$ & $<0.05^{* *}$ \\
\hline $\begin{array}{l}\text { Duration of } \\
\text { disease }\end{array}$ & $13.7 \pm 11.1$ & $8.2 \pm 7.8$ & $<0.05^{* *}$ \\
\hline Hypertension & $\begin{array}{c}\text { Present } \\
(n=81)\end{array}$ & $\begin{array}{l}\text { Absent } \\
(n=482)\end{array}$ & $\mathbf{P}$ \\
\hline Female/male & $47 / 34$ & $256 / 226$ & $>0.05^{*}$ \\
\hline Age† & $43.5 \pm 22.4$ & $40.7 \pm 8.1$ & $>0.05^{* *}$ \\
\hline PASI score & $5.1 \pm 4.6$ & $6 \pm 3.8$ & $>0.05^{* *}$ \\
\hline $\begin{array}{l}\text { Duration of } \\
\text { disease }\end{array}$ & $8.9 \pm 4.1$ & $8.4 \pm 4.8$ & $>0.05^{* *}$ \\
\hline Dyslipidemia & $\begin{array}{l}\text { Present } \\
(n=105)\end{array}$ & $\begin{array}{l}\text { Absent } \\
(n=458)\end{array}$ & $\mathbf{P}$ \\
\hline Female/male & $64 / 41$ & $239 / 219$ & $>0.05^{*}$ \\
\hline Age† & $43.8 \pm 18.1$ & $38.9 \pm 12.7$ & $>0.05^{* *}$ \\
\hline PASI score & $5.1 \pm 3.4$ & $4.3 \pm 4.2$ & $>0.05^{* *}$ \\
\hline $\begin{array}{l}\text { Duration of } \\
\text { disease }\end{array}$ & $12.4 \pm 10.8$ & $8.9 \pm 8.2$ & $>0.05^{* *}$ \\
\hline Diabetes & $\begin{array}{c}\text { Present } \\
(n=52)\end{array}$ & $\begin{array}{c}\text { Absent }(n= \\
511)\end{array}$ & $\mathbf{P}$ \\
\hline Female/male & $39 / 13$ & $264 / 247$ & $<0.05^{*}$ \\
\hline Age† & $41.2 \pm 18.1$ & $39.3 \pm 9.7$ & $>0.05^{* *}$ \\
\hline PASI score & $4.9 \pm 4.7$ & $4.2 \pm 3.2$ & $<0.05^{* *}$ \\
\hline $\begin{array}{l}\text { Duration of } \\
\text { disease }\end{array}$ & $10.9 \pm 10.8$ & $9 \pm 9.8$ & $>0.05^{* *}$ \\
\hline
\end{tabular}

† year

* Chi-square test, obesity, $\chi^{2}=26.7$; hypertension, $\chi^{2}=24.3$; dyslipidemia, $\chi^{2}=12.8$; diabetes, $\chi^{2}=29.8$

** Student's t- test 
Psoriasis was more severe in smokers $(\mathrm{p}<0.05)$, however, the duration of disease $(\mathrm{p}>0.05)$ and gender distribution did not show a statistically significant difference $\left(\chi^{2}=3.2, p>0.05\right)$. The relationship between these parameters and alcohol use and comorbid diseases was not evaluated due to the small number of patients.

\section{DISCUSSION}

In our study, MBS prevalence was $12.6 \%$ in psoriasis patients. Bayram et al screened 7148 individuals in a study which was planned by the Hypertension Task Force of Turkish Endocrinology and Metabolism Association and found a prevalence for MBS of $40.1 \%$ in females and $25.2 \%$ in males, with an overall of $34.9 \% .{ }^{23} \mathrm{Ac}-$ cording to the data from the Turkish Metabolic Syndrome Research, conducted in 2004 through screening of 4264 individuals, MBS prevalence was $41.1 \%$ in females, $28.8 \%$ in males, with an overall of $35 \% .{ }^{24}$ Günaydın et al ${ }^{2}$ had found MBS in 31 (62\%) of 50 psoriasis patients when they evaluated MBS components with laboratory investigations including fasting blood glucose, among others. Lower ratios found in our study may have resulted from the assessment of MBS components like diabetes, dyslipidemia and hypertension only in diagnosed patients. The difference between the MBS ratios in these two studies also indirectly indicates the presence of undiagnosed patients in respect to MBS components or those who are unaware of their disease in the population of psoriasis patients. Higher prevalence of MBS in females among psoriasis patients is consistent with the higher prevalence of MBS in females in our country. ${ }^{23,24}$ This ratio varies between $4.5 \%$ and $38.6 \%$ in other studies conducted with psoriasis patients. ${ }^{10,11,16,17}$ MBS prevalence may vary between countries due to the differences in genetic and environmental factors and life style. However, other factors may also contribute to MBS prevalence in our study population. One of them is the lower mean age of our patients compared to other series. ${ }^{10,11}$ MBS prevalence is reported to increase with age. ${ }^{11,17} \mathrm{~A}$ higher mean age of psoriasis patients with MBS in our study emphasizes the relationship between MBS risk and age and suggests that MBS should be evaluated particularly in the older psoriasis patients. Gisondi et al reported that MBS is a risk factor mainly for psoriasis patients above 40 years of age. ${ }^{11}$ All of our cases being above 40 years validates this data. Another reason for a lower ratio of patients with MBS in our study is lower PASI score of our patients and presence of severe psoriasis (PASI score $>10$ ) in only one-third of the patients. ${ }^{10,11}$ Belincon et $a l^{17}$ found a prevalence of MBS of $37.5 \%$ in severe psoriasis patients who had the indication of systemic treatment. Sommer et $a l^{10}$ reported MBS prevalence as $30 \%$ in hospitalized psoriasis population whose mean PASI score was 11 . These data indicate that MBS prevalence may be associated with psoriasis severity. ${ }^{5,9,14,16}$ In our study, although a difference was not found between psoriasis patients with or without MBS with regard to disease severity, PASI score was greater than 10 in all patients with MBS. The relationship between MBS and long duration of disease which we detected in our study was also reported in previous studies. ${ }^{10}$

The first suggestion about the relationship between MBS and psoriasis is impairment in T-cell pathways in both conditions. Another is the impaired quality of life and altered behaviors like poor eating habits, alcohol, stress, avoidance of physical activity and thereby direct association with the development of some MBS components. ${ }^{5,9,11}$ The main components of MBS are obesity, hyperlipidemia, hypertension, and diabetes. In our study, obesity was detected in $38.7 \%$ of psoriasis cases, hyperlipidemia in $18.6 \%$, diabetes in $9.2 \%$ and hypertension in $14.3 \%$.

The relationship between psoriasis and obesity was first considered to result from the patients' isolation from the society, preferring a sedentary life, due to the negative effects of psoriasis on quality of life. ${ }^{9,12}$ However, publications are available about the similarities between the pathophysiology of obesity and psoriasis. ${ }^{4}$ It was claimed that obesity emerges in the course of psoriasis, and that the inflammatory process leading to psoriasis contributes to the development of obesity; this was considered to result from a higher prevalence of obesity in psoriasis patients compared to the general population. . $^{6,9,12}$

BMI was higher in psoriasis patients, particularly in women. ${ }^{10}$ In the Turkish Diabetes, Obesity and Hypertension Epidemiology (TURDEP) study conducted in 1999, 24,788 individuals were screened and obesity prevalence was $29.9 \%$ in females, $12.9 \%$ in males, with an overall $22.3 \% .{ }^{25}$ Onat et al reported obesity prevalence as $44.2 \%$ in adult females and 25.2 in males in the Heart Diseases and Risk Factors in Turkish Adults Study. ${ }^{26}$ Obesity prevalence was $38.7 \%$ in psoriasis patients in our study; this ratio is higher than the reported for our country. However, it is not possible to state that obesity prevalence is higher among psoriasis patients compared to the general population as we do not have an age-matched control group. Obesity prevalence was higher in female psoriasis patients in our study as in the population-based studies conducted in our country.

Various hypotheses are present about the relationship between adipose tissue and psoriasis. Many recent studies have shown chronic mild inflammation caused by obesity, with high levels of TNF- $\alpha$, IL- 6 , and C-reactive protein associated with an increase in BMI. These proinflammatory cytokines might also influence the course and presentation of psoriasis. ${ }^{27}$ The findings which suggest that cutaneous inflammation and neighboring fat tissue cytokines could induce hyper-proliferation of each other are as follows; i. ${ }^{2-4}$ Definition of the receptors which mediate early immune response to antigens on the cell surface of adipocytes and release cytokines like interleukin-6 and tumor necrosis factor (TNF)-alpha, which are closely related to psoriasis development, ii. Higher production of circulating TNF- $\alpha$, soluble TNF- $\alpha$, and in vitro TNF- $\alpha$ in the obese compared to the non-obese, iii. Differences in T-cell responses developing after weight loss in the obese, iv. Adipose tissue cytokine leptin (which has an important role in natural and adaptive immune response) stimulating $\mathrm{T}$ lymphocyte response. v. Weight loss and obesity control both in murine experimental models and in humans with psoriasis improve the severity of the disease. ${ }^{27}$ vi. The use of drugs that improve insulin resistance, such as pioglitazone, also improve plaque psoriasis. ${ }^{27}$ All these data indicate the potential relationship between obesity and risk for the development of psoriasis. Naldi et al showed that psoriasis was seen 1.9 fold greater in individuals whose $\mathrm{BMI}>30 .{ }^{20}$

In our study, when compared to the non-obese patients, mean PASI score were higher and disease duration was longer in obese psoriasis patients. The observation that severe psoriasis vari- 
ants were more frequent in obese psoriasis patients was also shown in other studies. ${ }^{5,17,25}$ Duarte et al demonstrated that the severity of psoriasis measured by PASI presents a significant correlation with BMI, waist-to-hip ratio and waist circumference measurements. ${ }^{28}$ They also found an association between the severity of psoriasis based on PASI scores and BMI scores of $>25$ and $>30$. Sakai et al reported that BMI $>25$ on admission was a factor which influenced long-term prognosis in their study, where they followed up 169 psoriasis patients for longer than ten years, and proposed that BMI can be used as a prognostic index for psoriasis. ${ }^{29}$ On the other hand, some authors indicate that BMI is not adequate for different ethnicities/ages, muscle mass levels, bone structure and not measuring central adiposity. In a Brazilian study, the waist-to-height ratio was evaluated in a sample of 297 psoriasis patients and a significant correlation with BMI and PASI was found. ${ }^{30}$

In parallel to the efforts to find biomarkers of psoriasis severity, levels of various cytokines or chemokines have been examined and it was found out that osteopontin, CCL5 and CXCL9 levels in psoriasis patients were higher than those observed in the control group and were not affected by obesity. Duarte et al proposed that osteopontin possibly participated in the pathogenesis of inflammatory and metabolic conditions associated with obesity, including non-alcoholic fatty liver disease and atherosclerosis, more than reflecting high BMI per se. ${ }^{31}$ According to their results, the absence of a relationship between osteopontin and the production of inflammatory cytokines and chemokines emphasized the importance of osteopontin in the pathogenesis of psoriasis and as a psoriasis biomarker. $^{31}$

The relationship between hypertension and psoriasis is reported in the studies of Lindegard, Henseler and Christophers, Kothiwala. ${ }^{6,732}$ Despite the papers which emphasize the coexistence of hypertension and particularly psoriasis, hypertension was detected in $14.3 \%$ in our psoriasis patients but was not found to be associated with disease severity or duration. ${ }^{10}$ It was proposed that hypertension in psoriasis patients could be associated with endothelin-1. Endothelin-1, an autocrine growth factor produced by keratinocytes, is found in large amounts in psoriatic lesions and correlated with disease severity. It is suggested that endothelin leads to hypertension through a systemic vasoconstrictive effect. ${ }^{3}$

Studies are available showing that lipid metabolism changes are more common in psoriasis patients compared to normal population. ${ }^{13,14,33-35}$ Dreiher et al researched lipid abnormalities in 10,669 psoriasis patients and 22,996 healthy subjects and detected that lipid disorders are 1.48 fold greater in psoriasis patients. ${ }^{13}$ Dyslipidemia was detected in $18.6 \%$ of our patients; dyslipidemia was not found to be related to disease duration and disease severity. The association between lipid profile impairment and psoriasis severity is controversial. ${ }^{13,14,26,29}$ Mallbris et al detected that HDL cholesterol is $15 \%$ greater and apolipoprotein A-1 is $11 \%$ greater in psoriasis patients, and there are differences in VLDL composition in psoriasis patients when they compared lipid profile of 200 psoriasis patients who were diagnosed within the previous 12 months and control group. ${ }^{14}$ They proposed that lipid changes were seen in a very early period of the disease and psoriasis patients tend to have lipid changes independently of disease severity and systemic treatments.
Diabetes prevalence among psoriasis patients was investigated in many studies and it was $8.2 \%$ in our study, and $4.3 \%$, $11.7 \%$ and $13.8 \%$ in other series. ${ }^{1,5-8,10,32}$ Psoriasis-diabetes coexistence is explained by chronic inflammation leading to endothelial dysfunction, glucose metabolism disorders and peripheral insulin resistance and thereby type 2 diabetes development; polymorphism in the genes which encode the receptors of glycosylation products in psoriasis patients or the effect of corticosteroids which are used in topical treatment of psoriasis. ${ }^{1,10}$ Coexistence of psoriasis-diabetes is more frequent among females as in our study and diabetes is usually seen in severe psoriasis patients.,

Psychosocial effects of psoriasis and the influence on the quality of life are worse than its physical effects. Negative approach of the social environment to the disease, chronic course of the disease, inability to cure and the economic burden of chronic disease lead to psychiatric disorders like depression and also lead to alcohol use, smoking, and poor nutrition habits. ${ }^{36}$

Publications are available showing that smoking influences psoriasis distribution (acral distribution), clinical variability (pustular variant) and course of the disease. ${ }^{16}$ Smoking causes an increase in oxidative stress, causes functional and morphologic changes in polymorphonuclear leukocytes and the release of chemotactic factors, and also stimulates the release of cytokines like interleukins, TNF- $\alpha$ and transforming growth factor (TGF)-beta, which have impact on psoriasis severity. ${ }^{17-19}$ Smoking prevalence was shown to be higher in psoriasis patients than in the normal population. . $^{12,17-19}$ The ratio of smokers among psoriasis patients is $20 \%{ }^{8}, 28 \%, 45.4 \%$, $65 \%$ in various series. ${ }^{5,8,10,19,37}$ This ratio was $50.3 \%$ in our study and $69.6 \%$ of our subjects smoked before the diagnosis of psoriasis. Similarly, Herron et al ${ }^{12}$ found a $78 \%$ ratio. A high ratio of smoking before the diagnosis of psoriasis suggests the relationship between smoking and risk for the development of psoriasis. In a study, risk for psoriasis development was shown to increase 1.9 fold in ex-smokers and 1.7 fold in current smokers compared to non-smokers. ${ }^{20}$ Naldi et al detected that smoking more than 15 cigarettes daily is related with psoriasis development. ${ }^{21}$ These results indicate that smoking is also a precipitating factor for psoriasis. This risk was detected only in female patients in some studies. ${ }^{19,38,39}$

In our study, smoking was also found to be related to psoriasis severity. Fortes et al detected that severe psoriasis risk increased $30 \%$ in smokers. Studies indicate that the duration of smoking or age of starting are not related to disease severity, ${ }^{22}$ but the number of daily smoked cigarettes. ${ }^{20-22}$ Risk for the development of severe psoriasis was two-fold greater in patients who smoke more than 20 cigarettes daily compared to the subjects who smoke less ( $<10 /$ day). This relationship is more prominent in females. ${ }^{22}$

The relationship between alcohol and psoriasis was less studied. Alcohol use is an important risk factor, particularly in male psoriasis patients. ${ }^{40,41}$ Alcohol use is reported to trigger psoriasis through an increase in trauma or infection. ${ }^{40-42}$ Effect of ethanol on lymphocyte transformation suggests that alcohol can also affect immune mechanisms. ${ }^{21}$

Alcohol use among psoriasis patients was reported as $22 \%$ and $24 \%$ in two studies. ${ }^{8,33}$ The ratio of alcohol use is only $3.3 \%$ in our study. We cannot make a comment about the relationship be- 
tween alcohol use and socio-cultural differences due to the absence of a control group. Publications are available reporting that alcohol use increases psoriasis severity, influences treatment negatively ${ }^{38,42}$ and increases psoriasis-related mortality. ${ }^{39}$

In $3.3 \%$ of our psoriasis patients there was a diagnosis of coronary artery disease. Th1 cytokines that are involved in chronic inflammation in psoriasis are thought to have role for an increased risk for the development of atherosclerosis and coronary artery diseases in these patients. . $^{3,5,10,11,43,44}$

The main common purpose of the studies investigating MBS-psoriasis relationship is to determine the pathways for treatment and to develop biologic treatments toward common key point mediators. ${ }^{45,46}$ In a study, pre-treatment interleukin-17 levels were investigated among psoriasis patients with or without MBS. The interleukin-17 levels, which were significantly high in both groups before treatment, decreased significantly in the group without MBS compared to the patients with MBS. ${ }^{45}$ This study, which indicates that interleukin-17-targeting treatments could provide an advantage in psoriasis patients with MBS, suggests that systemic treatment options which are determined according to the co-morbidities will progress to a further stage in the near future.

\section{CONCLUSIONS}

In conclusion, although coronary artery disease was detected in only $3.3 \%$ of our patients, the presence of $38.7 \%$ obesity and $50.3 \%$ smoking ratios indicate that these patients are at risk for the development of metabolic and vascular disorders, mainly cardiovascular diseases and type 2 diabetes. Our results indicate that MBS is a risk factor for psoriasis patients with advanced age and with longer disease duration. The relationship between disease severity and obesity, diabetes, and smoking in psoriasis patients indicates that the patients should be informed about the potential metabolic risks and receive therapies for behavioral changes besides anti-psoriatic treatment to minimize these risks. $\square$

\section{REFERENCES}

1. Cohen AD, Dreiher J, Shapiro Y, Vidavsky L, Vardy DA, Davidovici B. Psoriasis and diabetes: a population-based cross-sectional study. J Eur Acad Dermatol Venereol. 2008;22:585-9.

2. Günaydın A, Aytimur D, Özdemir F. Psoriasis ve metabolik sendrom. Türkderm. 2014;48:95-9.

3. Guenther L, Gulliver W. Psoriasis comorbidities. J Cutan Med Surg 2009;13:S77-87.

4. Duarte GV, Follador I, Cavalheiro CM, Silva TS, Oliveira Mde F. Psoriasis and obesity: literature review and recommendations for management. An Bras Dermatol. 2010;85:355-60.

5. Neimann AL, Shin DB, Wang X, Margolis DJ, Troxel AB, Gelfand JM. Prevalence of cardiovascular risk factors in patients with psoriasis. J Am Acad Dermatol. 2006:55:829-35.

6. Lindegard B. Diseases associated with psoriasis in a general population of 159,200 middle-aged, urban, native Swedes. Dermatologica. 1986;172:298-304

7. Henseler T, Christophers E. Disease concomitance in psoriasis. J Am Acad Dermatol. 1995;32:982-6.

8. Pearce DJ, Morrison AE, Higgins KB, Crane MM, Balkrishnan R, Fleischer AB Jr, et al. The comorbid state of psoriasis patients in a university dermatology practice. $J$ Dermatolog Treat. 2005;16(5-6):319-23.

9. Cohen AD, Sherf M, Vidavsky L, Vardy DA, Shapiro J, Meyerovitch J. Association between psoriasis and the metabolic syndrome. A cross-sectional study. Dermatology 2008;216:152-5.

10. Sommer DM, Jenisch S, Suchan M, Christophers E, Weichenthal M. Increased prevalence of the metabolic syndrome in patients with moderate to severe psoriasis. Arch Dermatol Res. 2006;298:321-8.

11. Gisondi P, Tessari G, Conti A, Piaserico S, Schianchi S, Peserico A, et al. Prevalence of metabolic syndrome in patients with psoriasis:a hospital-based case-control study. Br J Dermatol. 2007;157:68-73.

12. Herron MD, Hinckley M, Hoffman MS, Papenfuss J, Hansen CB, Callis KP, et al. Impact of obezity and smoking on psoriasis presentation and management. Arch Dermatol 2005;141:1527-34

13. Dreiher J, Weitzman D, Davidovici B, Shapiro J, Cohen AD. Psoriasis and dyslipidaemia:a population-based study. Acta Derm Venereol. 2008;88:561-5.

14. Mallbris L, Granath F, Hamsten A, Ståhle M. Psoriasis is associated with lipid abnormalities at the onset of skin disease. J Am Acad Dermatol. 2006:54:614-21.

15. Shahwan KT, Kimball AB. Psoriasis and Cardiovascular Disease. Med Clin North Am. 2015:99:1227-42.

16. Malkic Salihbegovic E, Hadzigrahic N, Cickusic AJ. Psoriasis and metabolic syndrome. Med Arch 2015;69:85-7.

17. Belinchón I, Vanaclocha F, de la Cueva-Dobao P, Coto-Segura P, Labandeira J, Herranz P, et al. Metabolic syndrome in Spanish patients with psoriasis needing systemic therapy:Prevalence and association with cardiovascular disease in PSORISK, a cross-sectional study. J Dermatolog Treat. 2015;26:318-25.

18. Zimmet P, Magliano D, Matsuzawa Y, Alberti G, Shaw J. The metabolic syndrome: a global public health problem and a new definition. J Atheroscler Thromb. 2005:12:295-300

19. Naldi L. Cigarette smoking and psoriasis. Clin Dermatol. 1998;16:571-4.

20. Naldi L, Chatenoud L, Linder D, Belloni Fortina A, Peserico A, Virgili AR, et al. Cigarette smoking, body mass index, and stressful life events as risk factors for psoriasis:results from an Italian case-control study. J Invest Dermatol. 2005; $125: 61-7$

21. Naldi L, Peli L, Parazzini F. Association of early-stage psoriasis with smoking and male alcohol consumption:evidence from an Italian case-control study. Arch Dermatol. 1999;135:1479-84.

22. Fortes C, Mastroeni S, Leffondré K, Sampogna F, Melchi F, Mazzotti E, et al. Relationship between smoking and the clinical severity of psoriasis. Arch Dermatol. 2005:141:1580-4

23. Bayram F, Gündoğan K, Öztürk A, Yazıcı C. Prevalence of metabolic syndrome in the world and Turkey. Turkiye Klinikleri J Int Med Sci. 2006;2:18-24.

24. Abacı A. The current status of cardiovascular risk factors in Turkey. Arch Turk Soc Cardiol. 2011;39:1-5.

25. Satman I, Yilmaz T, Sengül A, Salman S, Salman F, Uygur S, et al. Populationbased study of diabetes and risk characteristics in Turkey: results of the Turkish diabetes epidemiology study (TURDEP). Diabetes Care. 2002;25:1551-6.

26. Onat A, Keleş I, Sansoy V, Ceyhan K, Uysal Ö, Çetinkaya A, et al. Rising obesity indices in 10-year follow-up of turkish men and women: body mass index independent predictor of coronary events among men. Arch Turk Soc Cardiol 2001:29:430-6

27. Oliveira Mde F, Rocha Bde 0, Duarte GV. Psoriasis: classical and emerging comorbidities. An Bras Dermatol. 2015;90:9-20.

28. Duarte GV, Oliveira Mde F, Cardoso TM, Follador I, Silva TS, Cavalheiro CM, et al. Association between obesity measured by different parameters and severity of psoriasis. Int J Dermatol. 2013;52:177-81.

29. Sakai R, Matsui S, Fukushima M, Yasuda H, Miyauchi H, Miyachi Y. Prognostic factor analysis for plaque psoriasis. Dermatology. 2005;211:103-6.

30. Duarte GV, Silva LP. Correlation between psoriasis' severity and waist-to-height ratio. An Bras Dermatol. 2014;89:846-7.

31. Duarte GV, Boeira V, Correia T, Porto-Silva L, Cardoso T, Macedo MN. Osteopontin, CCL5 and CXCL9 are independently associated with psoriasis, regardless of the presence of obesity. Cytokine. 2015;74:287-92.

32. Kothiwala SK, Khanna N, Tandon N, Naik N, Sharma VK, Sharma S, et al. Prevalence of metabolic syndrome and cardiovascular changes in patients with chronic plaque psoriasis and their correlation with disease severity: A hospitalbased cross-sectional study. Indian J Dermatol Venereol Leprol. 2016:82:510-8.

33. Uyanik BS, Ari Z, Onur E, Gündüz K, Tanülkü S, Durkan K. Serum lipids and apolipoproteins in patients with psoriasis. Clin Chem Lab Med. 2002;40:65-8. 
34. Seçkin D, Tokgözoğlu L, Akkaya S.Are lipoprotein profile and lipoprotein (a) levels altered in men with psoriasis? J Am Acad Dermatol. 1994;31:445-9.

35. Piskin S, Gurkok F, Ekuklu G, Senol M. Serum lipid levels in psoriasis. Yonsei Med J. 2003;44:24-6

36. Gupta MA, Gupta AK. Psychodermatology:An update. J Am Acad Dermatol. 1996;34:1030-46.

37. Zheng GY, Wei SC, Shi TL, Li YX. Association between alcohol, smoking and HLA-DQA1*0201 genotype in psoriasis. Acta Biochim Biophys Sin (Shanghai). 2004:36:597-602.

38. Poikolainen K, Reunala T, Karvonen J. Smoking, alcohol and life events related to psoriasis among women. Br J Dermatol. 1994:130:473-7.

39. Poikolainen K, Karvonen J, Pukkala E. Excess mortality related to alcohol and smoking among hospital-treated patients with psoriasis. Arch Dermatol. 1999;135:1490-3.

40. Zhang X, Wang H, Te-Shao H, Yang S, Wang F. Frequent use of tobacco and alcohol in Chinese psoriasis patients. Int J Dermatol. 2002;41:659-62.
41. Deveci A, Ermertcan A, Deniz F, Madak BG, Öztürkcan S. Psoriasisli Hastalarda Alkol Kullanımı Ve İnthhar Olasılı̆ı. Türkiye Psikiyatri Dergisi. 2007;9:103-7.

42. Gupta MA, Schork NJ, Gupta AK, Ellis CN. Alcohol intake and treatment responsiveness of psoriasis:a prospective study. J Am Acad Dermatol. 1993;28:730-2.

43. Mallbris L, Akre 0, Granath F, Yin L, Lindelöf B, Ekbom A, et al. Increased risk for cardiovascular mortality in psoriasis inpatients but not outpatients. Eur $\mathrm{J}$ Epidemiol. 2004:19:225-30.

44. Gelfand JM, Neimann AL, Shin DB, Wang X, Margolis DJ, Troxel AB. Risk of myocardial infarction in patients with psoriasis. JAMA. 2006;296:1735-41.

45. Coimbra S, Oliveira H, Neuparth MJ, Proença JB, Figueiredo A, Rocha-Pereira P, et al. Metabolic syndrome in psoriasis patients. Residual inflammation and proinflammatory IL17 signaling reduce length of remission. A follow-up study. Br J Dermatol. 2016;174:414-6.

46. Voiculescu VM, Lupu M, Papagheorghe L, Giurcaneanu C, Micu E. Psoriasis and Metabolic Syndrome--scientific evidence and therapeutic implications. J Med Life. 2014;7:468-71.

How to cite this article: Adışen E, Uzun S, Erduran F, Gürer MA. Prevalence of smoking, alcohol and metabolic syndrome in patients with psoriasis. An Bras Dermatol. 2018;93(2):205-11. 